\title{
Corpos (des)conectados e o professor de Educação Física escolar: contribuições das mídias e tecnologias digitais
}

\author{
(Dis)connected bodies and the school Physical Education teacher: contributions from \\ digital media and technologies
} Cuerpos (des)conectados y el profesor de Educación Física de la escuela: contribuciones de
medios y tecnologías digitales

Alan Camargo Silva ${ }^{\mathrm{I}}$

\begin{abstract}
Resumo
Este manuscrito é uma resenha do livro intitulado "Formação continuada em Educação Física no diálogo com a cultura digital", publicado pelo Instituto Federal da Paraíba, Brasil, em 2019. Os organizadores dessa coletânea digital (Allyson Carvalho de Araújo, Márcio Romeu Ribas de Oliveira e Antonio Fernandes de Souza Junior) trazem textos inéditos sobre a importância da formação continuada de docentes de Educação Física que atuam no âmbito formal da área, perante o atual contexto da cibercultura. Exemplarmente, a obra apresenta limites e potencialidades em lidar com o corpo no ambiente da Educação em interface com o campo da Comunicação.
\end{abstract}

Palavras-chave: Educação Física; Formação Continuada; Docentes; Internet

\begin{abstract}
This manuscript is a review of the book entitled "Continuing Education in Physical Education in the Dialogue with Digital Culture", published by Federal Institute of Paraíba, Brazil, in 2019. The organizers of this book (Allyson Carvalho de Araújo, Márcio Romeu Ribas de Oliveira and Antonio Fernandes de Souza Junior) bring unpublished texts on the importance of continuing education for Physical Education teachers who work in the formal scope of the area, in the current context of cyberculture. Exemplarily, the book presents limits and potential in working with the body in the Education environment, in an interface with Communication field.
\end{abstract}

Keywords: Physical Education; Continuing Education; Teachers; Internet

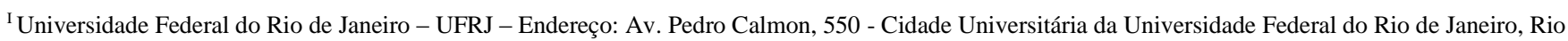
de Janeiro - RJ, CEP: 21941-901, Brasil - e-mail: alan10@zipmail.com.br
} 


\section{Resumen}

Este manuscrito presenta la reseña del libro "Educación continua en Educación Física en diálogo con la cultura digital" publicado por el Instituto Federal de Paraíba en 2019. Los organizadores del libro (Allyson Carvalho de Araújo, Márcio Romeu Ribas de Oliveira y Antonio Fernandes de Souza Junior) traen textos inéditos sobre la importancia de la formación \ continua para los profesores de Educación Física que trabajan en el ámbito formal del área, en el contexto actual de la cibercultura. Ejemplarmente, el trabajo tiene límites y potencialidades en el trato con el cuerpo en el contexto educativo, en interfaz con el campo de la comunicación.

Palavras clave: Educación Física; Educación Continua; Docentes; Internet

\section{Formação continuada em Educação Física no diálogo com a cultura digital}

O presente livro adentra em um subcampo da área ainda pouco explorado. De forma robusta, os responsáveis pela coletânea objetivam aproximar a área de Educação Física escolar às mídias e tecnologias digitais, exercício didático-pedagógico na formação continuada necessário no atual mundo atravessado pela cibercultura (LÉVY, 1999).

A ação de parceria articulada entre o Laboratório de Estudos em Educação Física, Esporte e Mídia da Universidade Federal do Rio Grande do Norte e a Secretaria de Educação da cidade permitiu que essa obra, de acesso aberto, se tornasse uma leitura indispensável para os professores de Educação Física que atuam no âmbito formal. Embora os processos de formação continuada de professores de Educação Física sejam fundamentais para o desenvolvimento de ensino-aprendizagem, no que diz respeito à qualificação acerca das mídias e tecnologias digitais (SILVEIRA; PIRES, 2019), por vezes, podem não levar em consideração as especificidades locais da comunidade escolar (FREITAS et al., 2016).

Em primeiro lugar, o livro em tela abre frentes de discussões e reflexões na Educação Física em interface com o campo da Educação e da Comunicação, interseções epistemológicas que, cada vez mais, podem consolidar-se nas formações iniciais da área (ARAÚJO, 2020). Em segundo lugar, a coletânea problematiza como o binômio mídia-educação pode atravessar o cotidiano docente e, por consequência, a realidade escolar dos alunos, o que já vem sendo visto, de certo modo, com uma abordagem metodológica relevante para a Educação Física (SOUZA JUNIOR, 2018). Além disso, os textos se preocupam em abordar conceitos acerca da temática, que podem fazer pensar os limites e as potencialidades dos saberes e das práticas dos professores da área no que diz respeito à cultura digital, o que "poderá proporcionar sólidas bases teórico-metodológicas para que a mídia e as novas tecnologias digitais sejam apropriadas e ressignificadas na sua interface com os conteúdos da Educação Física" (PIRES; LAZZAROTTI FILHO; LISBÔA, 2012). 
Destarte, a coletânea "Formação continuada em Educação Física no diálogo com a cultura digital" contém cinco capítulos. Ao mesmo tempo em que há a utilização de uma linguagem simples e, por vezes, com exemplos práticos que ilustram as experiências docentes, os capítulos são instigantes ao propor referenciais teórico-metodológicos da mídia e das tecnologias digitais durante o cotidiano da Educação Física escolar.

No capítulo introdutório, “Aproximações da formação continuada em Educação Física com as mídias e tecnologias: uma proposta mediada pelos conceitos", aborda-se a relevância de práticas pedagógicas inovadoras na Educação Física em diálogo com o campo da Comunicação. Os(as) autores(as) traçam um panorama acerca das práticas educacionais na escola, no que diz respeito à cultura digital. O capítulo argumenta sobre a escassez de iniciativas acadêmicas e profissionais voltadas ao trabalho pedagógico com base nas mídias e tecnologias na área de Educação Física, assim como, defende que a formação continuada se torna um artifício importante para o aprimoramento das aulas e que se desenvolva com base em aspectos teórico-práticos.

O segundo capítulo, "Sobre comunicação na Educação Física escolar”, trata especificamente sobre como atuar com a Educação Física por "outras vias comunicacionais”, tendo como base determinadas tecnologias. Segundo os relatos de uma formação continuada, e partindo da noção de corporeidade em que entende o corpo em constante interação com o mundo, o capítulo provoca o leitor no sentido de como ocorrem "novos processos de subjetivação" dos sujeitos por meio das mídias e das tecnologias digitais atualmente. Para os(as) autores(as), a dimensão comunicacional na área de Educação Física precisa evitar o distanciamento entre a prática pedagógica e a utilização dos recursos digitais, a fim de compreender a conhecida "sociedade midiática". O texto aponta que há uma sociedade com dificuldades de comunicação em que as "deixas simbólicas do corpo" parecem ficar secundarizadas diante das inúmeras informações da "era digital".

"Reflexões da aplicação das narrativas midiáticas na formação continuada dos professores de Educação Física" é o título do terceiro capítulo. Nesse texto, as autoras apontam como diferentes construções de discursos das mídias fazem parte do cotidiano pedagógico do professor de Educação Física escolar. As autoras do capítulo destacam a necessidade de compreensão e debate crítico por parte dos docentes sobre as narrativas midiáticas com seus alunos. O capítulo traz diferentes experiências dos professores de Educação Física para pensar o processo de ensino-aprendizagem a partir de distintos suportes midiáticos e tecnológicos.

No quarto capítulo, intitulado "Como as mídias atravessam a escola? Debatendo o conceito de mediação", os autores problematizam o fenômeno midiático no âmbito educacional. Em especial, o 
capítulo traz os possíveis obstáculos e também as oportunidades dialógicas de se trabalhar com as mídias na escola, a partir de experiências docentes de Educação Física. Em resumo, mais do que apropriar-se instrumentalmente das mídias e das tecnologias digitais, os autores convidam o leitor para pensar as mediações na área em termos socioculturais do consumo de tais recursos.

Já, no quinto e último capítulo, "Gamificação e Educação Física escolar: debatendo conceitos e compartilhando possibilidades", pode-se apreender algumas perspectivas, reflexões e experiências de professores diante dos jogos digitais. O capítulo trata criticamente a utilização de games na prática docente em Educação Física, em (co)construção do conhecimento com o aluno. Estratégias pedagógicas com base nesses tipos de jogos são interessantes na atuação docente, haja vista que a linguagem e a própria dinâmica dos games perpassam, de algum modo, a vida do público escolar.

Em síntese, a partir da obra, questiona-se até que ponto os corpos estão conectados ou desconectados com a realidade social e institucional. Entende-se que o livro consegue demonstrar que os corpos discentes que transitam presencialmente nos pátios, nas quadras e nas salas de aula são os mesmos que interagem no ciberespaço (LÉVY, 1999). Na contemporaneidade, professores de Educação Física sensíveis às questões e demandas do século XXI, marcado fundamentalmente pelo "virtual" ou "tecnológico", pautam seus saberes e práticas no cotidiano daqueles com quem atuam. Dessa maneira, entender os jovens como sujeitos sociais significa alinhavar um trabalho pedagógico ou um repensar curricular à realidade experiencial dos alunos (ARROYO, 2013).

Assim, orientados e mediados por docentes afetados pela cultura digital, o corpo e as práticas corporais nas aulas de Educação Física conseguem ser trabalhados com base no "chão da escola". Ainda que haja possíveis especificidades locais em determinadas instituições escolares, em termos socioeconômicos e culturais, torna-se imperativo exercer um trabalho ou uma ação pedagógica que leve em consideração a realidade das mídias e tecnologias digitais na disciplina Educação Física.

Portanto, diante desse contexto educativo corpóreo-social, ou, nas palavras de Lüdorf (2019), diante de uma "educação sociocorporal", argumenta-se aqui a necessidade de mais trabalhos voltados à cultura digital na Educação Física escolar. A obra brinda o leitor justamente com a ideia de indicar ou fornecer possibilidades de atuação para/ com/ no corpo ou com as práticas corporais a partir dos próprios docentes da disciplina.

Em suma, a coletânea diferencia-se do que vem sendo produzido na área em termos acadêmicoprofissionais. Se, por um lado, o livro limita-se a poucos textos que poderiam ser aprofundados em seus formatos e conteúdos, por outro, exemplarmente, caracteriza-se por um marco importante na área de 
Educação Física e suas relações com a mídia e as tecnologias digitais, ao abrir possibilidades de investigação de pesquisas e/ ou de atuação docente.

\section{Referências}

ARAÚJO, Allyson Carvalho de. Formação de professores e cultura digital na Educação Física: reflexes a partir do livro Being self-study researchers in a digital world: future oriented research and pedagogy in teacher education. Motrivivência, Florianópolis, v. 32, n. 61, p. 1-9, 2020. Disponível em: https://periodicos.ufsc.br/index.php/motrivivencia/article/view/2175-8042.2020e57707. Acesso em: 21 mai. 2020.

ARROYO, Miguel. Currículo, território em disputa. 5. ed. Petrópolis: Vozes, 2013.

FREITAS, Daniel Cesar et al. Formação continuada de professores de Educação Física. Corpoconsciência, Cuiabá, v. 20, n.3, p. 9-21, 2016. Disponível em: http://periodicoscientificos.ufmt.br/ojs/index.php/corpoconsciencia/article/view/4419. Acesso em:

21 mai. 2020.

LÉVY, Pierre. Cibercultura. São Paulo: Editora 34. 1999.

LÜDORF, Sílvia Maria Agatti. Corpo e Educação Física: por uma educação sociocorporal. In: SILVA, Marco; ORLANDO, Cláudio; ZEN, Giovana (Orgs.). Didática: abordagens teóricas contemporâneas. Salvador: EDUFBA, 2019. p. 305-329.

PIRES, Giovani de Lorenzi; LAZZAROTTI FILHO, Ari; LISBÔA, Mariana Mendonça. Educação Física, mídia e tecnologias: incursões, pesquisa e perspectivas. Kinesis, Santa Maria, v. 30, n. 1, p. 55-79, 2012. Disponível em: https://periodicos.ufsm.br/kinesis/article/view/5723. Acesso em: 21 mai. 2020.

SILVEIRA, Juliano; PIRES, Giovani de Lorenzi. Formação continuada em Educação Física e tecnologias digitais: percepções dos professores participantes. Corpoconsciência, Cuiabá, v. 23, n. 2, p. 49-62, 2019. Disponível em: http://periodicoscientificos.ufmt.br/ojs/index.php/corpoconsciencia/article/view/8505. Acesso em: 21 mai. 2020.

SOUZA JUNIOR, Antonio Fernandes de. Os docentes de Educação Física na apropriação da cultura digital: encontros com a formação continuada. 2018. 183 f. Dissertação (Mestrado em Educação Física), Universidade Federal do Rio Grande do Norte, Natal, 2018. Disponível em:

http://bdtd.ibict.br/vufind/Record/UFRN_649d328d0b5975cfdb0c752301ec2340. Acesso em: 21 mai. 2020.

\section{Como citar este artigo}

SILVA, A. C. Corpos (des)conectados e o professor de Educação Física escolar: contribuições das mídias e tecnologias digitais. Revista Kinesis, Santa Maria, v. 39, p.01-05, 2021.

* O presente trabalho não contou com apoio financeiro de nenhuma natureza para sua realização. 